\title{
Suppressive Effect of Catecholamines on 19-S Antibody Formation in Mouse Spleen Fragments in Vitro
}

\author{
Sohei Makino and Charles E. Reed* \\ Department of Medicine, Dokkyo University Medical School, \\ Mibu-machi, Tochigi-ken 321-02, Japan and *Department of \\ Medicine, Wisconsin University Medical School, Madison, \\ Wisconsin, U.S.A.
}

\begin{abstract}
Makino, S. and ReEd, C.E. Suppressive Effect of Catecholamines on 19-S Antibody Formation in Mouse Spleen Fragments in Vitro. Tohoku J. exp. Med., 1979, 127 (2), 143-149 _ Spleen fragments of Balb/C mice were immunized with sheep red blood cells in vitro and hemolytic plaque forming cells (PFC) were assayed on the 5th day of immunization. Epinephrine in culture medium diminished the number of PFC dose-dependently over the range from $10^{-6} \mathrm{M}$ to $2.7 \times 10^{-4} \mathrm{M}$. Incubation with $9 \times 10^{-5} \mathrm{M}$ epinephrine diminished $\mathrm{PFC}$ response only when the epinephrine was present on the first day of the culture. No suppression was found for treatment during any other $24 \mathrm{hr}$ periods. Three beta-adrenergic stimulating catecholamines, epinephrine, isoproterenol, and norepinephrine, suppressed PFC response in similar degree. It is concluded that beta-adrenergic stimulation suppressed 19-S antibody formation mainly by inhibiting induction of immune response. - beta-adrenergic stimulation; hemolytic plaque forming cell; organ culture; immunosuppression
\end{abstract}

Antigenic stimulation induces changes of intracellular level of cyclic AMP in lymphoid organs (Webb et al. 1977), and cyclic AMP has been considered to modulate antibody formation. Exogenous cyclic AMP has been reported to inhibit and also to stimulate antibody formation, depending on the dose of cyclic AMP, stage of antibody formation and its ratio to cyclic GMP (Ishizuka et al. 1970; Braun and Ishizuka 1971; Watson et al. 1973; Watson 1975; Johnson et al. 1977; Kishimoto et al. 1977).

Bronchial asthma is one of the atopic diseases and is often characterized by increased production of IgE antibody. Lymphocytes from patients with asthma show decreased response to beta-adrenergic stimulants (Makino et al. 1977; Lee et al. 1977). A possibility that subsensitivity of beta-adrenergic receptor may contribute to increased antibody formation in asthma prompted us to investigate the effects of beta-adrenergic stimulating catecholamines on antibody formation.

In the previous study, we found that beta-adrenergic blockers, propranolol and butoxamine, enhanced anti-hapten antibody formation in primary response in rats, suggesting that endogenous beta-stimulating catecholamines may suppress

Received for publication, March 27, 1978. 
antibody formation, and inversely blockade of beta-adrenergic receptor may enhance antibody formation (Reed et al. 1972).

Recently, Nakazawa et al. (1977) showed that the chronic beta-adrenergic blockade with propranolol enhanced IgE antibody formation in mice. Lymphocytes have beta-adrenergic receptors and the stimulation of the receptor with endogenous beta-stimulating catecholamines may modulate the functions of lymphocytes on antibody formation. Detailed investigations of catecholamines on antibody formation have not been reported.

The purposes of this report are to determine 1) whether catecholamines suppress antibody formation, and 2) at which stage of immunization catecholamines exert their effects.

Antibody formation was assessed by direct hemolytic plaque forming cells $(\mathrm{PFC})$ in mouse spleen fragments immunized with sheep red blood cells in vitro.

\section{MDTHOD}

Male Balb/C mice (Jackson Lab.) 1.5 to 6 months old received food and water ad libitum.

Organ culture for in vitro immunization was carried out by the method of Globerson and Auerbach (1966) with some modification. A mouse was sacrificed with ether or cervical dislocation. The spleen was removed immediately and cut into cuboidal fragments, approximately $0.4 \mathrm{~mm}$ on a side. Each of the fragments contained approximately $10^{8}$ lymphoid cells. Five to 7 spleen fragments were distributed on a membrane platform. The number of the fragments was the same in each experiment. Only one spleen yielding 15 to 25 culture dishes was used in each experiment. The membrane platform was prepared by gluing a Nucleopore filter (General Electrics, pore size $0.5 \mu$ ) to the underside of a $5 \times 5 \mathrm{~mm}$ hole in a plastic mount. The plastic assembly was placed in an organ culture dish (Falcon plastic $\$ 3037)$ ) containing approximately $1.2 \mathrm{ml}$ of tissue culture medium.

The culture medium consisted of Eagle's basal medium (Microbiological Associates) supplemented with 10\% agamma horse serum (Hyland), 5\% chicken embryo extract (9 day embyros), erythromycin $(50 \mu \mathrm{g} / \mathrm{ml})$, penicillin $(50 \mathrm{unit} / \mathrm{ml})$, streptomycin $(50 \mu \mathrm{g} / \mathrm{ml})$ and mycostatin $(50 \mu \mathrm{g} / \mathrm{ml})$. Culture dishes were incubated at $37.5^{\circ} \mathrm{C}$ in a water saturated atmosphare of air and $6 \%$ carbon dioxide. The culture medium in all dishes was exchanged every $24 \mathrm{hr}$. The spleen fragments were over-layed with $0.02 \mathrm{ml}$ of $1 \%$ sheep red blood cells (GIBCO), washed and resuspended in Tyrode's solution, 2 and $72 \mathrm{hr}$ after the start of incubation.

L-Epinephrine bitartrate (Sigma), L-norepinephrine bitartrate (Nutritional Biochemical Company) and L-isoproterenol bitartrate (Sigma) were dissolved in $0.15 \mathrm{M}$ sodium chloride solution containing ascorbic acid $(2 \mathrm{mg} / \mathrm{ml})$ to retard oxidation. Reagents were added to the culture medium in a volume of $10 \mu \mathrm{l}$ per $\mathrm{ml}$. The controls received the same volume of ascrobic acid saline solution. Stability of the catecholamines during incubation of the culture medium was determined by bioassay using the mouse uterus. The catecholamines at a concentration of $90 \mu \mathrm{M}$ remained almost undiminished in the tissue culture medium in the incubator for the first $14 \mathrm{hr}$ and then deteriorated.

The spleen fragments and the cells which had settled on the bottom of each diffusion chamber were transferred to a small glass tube containing $0.5 \mathrm{ml} 10 \%$ fetal calf serum in Tyrode solution and teased to prepare a cell suspension. The number of PFC in each culture were assayed by the technique of Cunningham and Szenberg (1968). The assay was carried out 5 days after immunization.

The number of $\mathrm{PFC}$ of each culture was expressed as the percentage of the mean of the corresponding control values, since the number varied markedly among animals used. 


\section{Resuths}

\section{Relation between PFC response and various doses of L-epinephrine}

Fresh medium containing various concentrations of epinephrine was supplied daily for 5 days. Epinephrine diminished the number of $\mathrm{PFC}$ and the diminution was dose-dependent over the range from $10^{-6} \mathrm{M}$ to $2.7 \times 10^{-4} \mathrm{M}$ (Fig. 1). No suppression was found at $10^{-7} \mathrm{M}$. The geometric mean and s.D. range of PFC in each control culture were 356 and 217-572 respectively. Background in cultures not stimulated with sheep red blood cells was 5 to $10 \mathrm{PFC} /$ culture. In 7 cultures examined, viability of the mononuclear cells was tested with trypan blue exclusion. The viability varied between 30 to 60 percent with a mean of 53 percent. There was no significant difference in viability between control cultures and that with $9 \times 10^{-5}$ M epinephrine, confirming reports on human peripheral blood lymphocytes (Patterson et al. 1976).

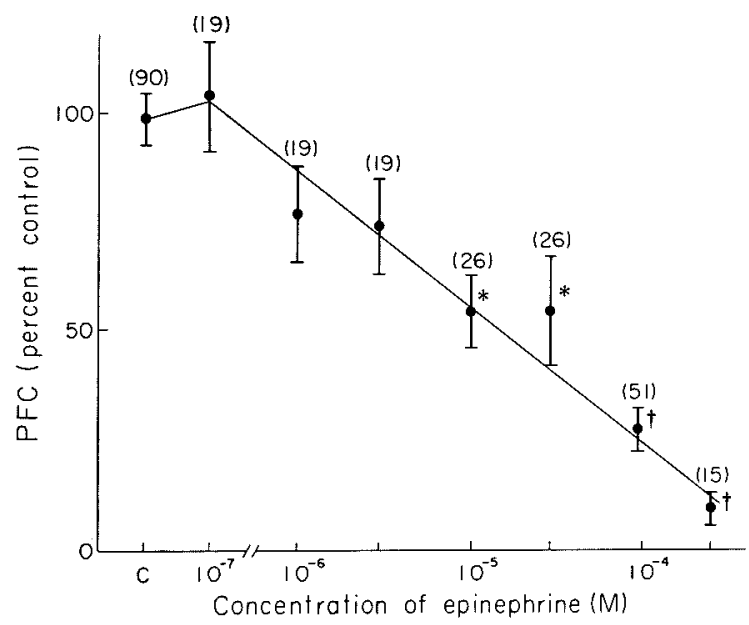

Fig. 1. Relation between PFC response and various doses of L-epinephrine. Points and vertical bars show the mean and standard error of $\mathrm{PFC}$ number expressed as percent of the mean of PFC number in corresponding control cultures. Number in parenthesis means the number of cultures examined. In $\mathrm{C}$ (control) no epinephrine was given.

* The difference from corresponding control culture was statistically significant at $p<0.05$.

$\dagger$ Statistically significant at $p<0.01$.

Effect of incubation with $9 \times 10^{-5} M$ L-epinephrine for $24 \mathrm{hr}$ on various days of the culture

Incubation with $9 \times 10^{-5} \mathrm{M}$ L-epinephrine diminished $\mathrm{PFC}$ response only when the epinephrine was present on the first day of the culture $(p<0.05)$. No significant suppression was found for any other 24-hr periods of the treatment (Fig. 2). The degree of the suppression was smaller, however, when epinephrine was present for only first $24 \mathrm{hr}$ than when it was present all over the entire 5 day-incubation period 


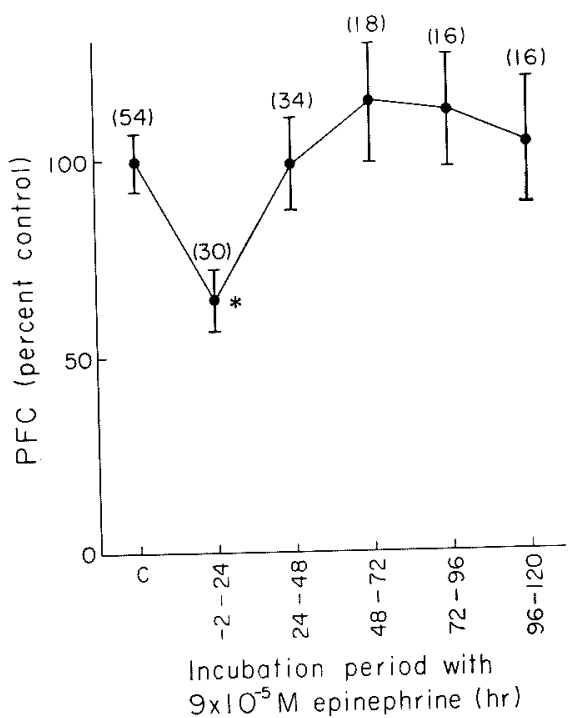

Fig. 2. Effect of incubation with $9 \times 10^{-5} \mathrm{M}$ L-epinephrine for $24 \mathrm{hr}$ on various days of the cultures. Other expressions are the same as in Fig. 1.

TABLE 1. Comparison of the effect of epinephrine, isoproterenol and norepinephrine on $P F C$ response

\begin{tabular}{lrr} 
& \multicolumn{2}{c}{ Concentration of catecholamines } \\
\cline { 2 - 3 } & \multicolumn{1}{c}{$1 \times 10^{-5} \mathrm{M}$} & \multicolumn{1}{c}{$9 \times 10^{-5} \mathrm{M}$} \\
\hline Control & $100.0 \pm 13.5^{*}(16)$ & $100.0 \pm 16.3(16)$ \\
Epinephrine & $66.1 \pm 8.7 \dagger(17)$ & $31.3 \pm 7.3^{\ddagger}(16)$ \\
Isoproterenol & $103.7 \pm 26.8(17)$ & $30.1 \pm 5.8^{\ddagger}(7)$ \\
Norepinephrine & $91.1 \pm 20.1(17)$ & $27.0 \pm 8.3_{+}^{+}(12)$ \\
\hline
\end{tabular}

* The mean and standard error of PFC number expressed as the percent of the mean of PFC number in control eultures. The number in parenthesis is the number of cultures examined.

$\dagger$ The difference from corresponding control cultures was statistically significant at $p<0.05$.

$\ddagger$ Statistically significant at $p<0.01$.

(Compare Fig. 1 and Fig. 2).

Effect of L-epinephrine, L-isoproterenol and L-norepinephrine.

Epinephrine, norepinephrine and isoproterenol are potent beta-adrenergic stimulating catecholamines. Isoproterenol almost lacks alpha-adrenergic stimulating effect. Fresh medium containing one of these catecholamines was supplied daily for 5 days. The degree of the suppression on PFC response was similar among these catecholamines at concentrations of $9 \times 10^{-5} \mathrm{M}$ (Table 1). 


\section{Comments}

Epinephrine suppressed 19-S antibody formation dose-dependently in vitro organ cultures as shown by decreased production of direct PFC in mouse spleen fragments. The suppression started at $10^{-6} \mathrm{M}$ and no suppression was present at $10^{-7} \mathrm{M}$. At $9 \times 10^{-5} \mathrm{M}$, other beta-adrenergic stimulating catecholamines, isoproterenol and norepinephrine, showed a similar degree of suppression of PFC response observed with epinephrine. These results suggest that beta-adrenergic stimulation present from the beginning of the immunization to the assay of PFC on day 5 suppresses antibody formation. Such observations were compatible with our prior finding of enhancement of antibody formation with beta-adrenergic blockade in vivo (Reed et al. 1972) and also with suppression of the in vitro antibody formation with exogenous cyclic AMP and theophylline (Watson et al. 1973).

We found that incubation of $9 \times 10^{-5} \mathrm{M}$ epinephrine during various $24 \mathrm{hr}$ periods suppressed immune response only on the first day, but not on the 2 nd to 5 th day. In the organ culture system used in the present study, Holterman and Nordin (1969) found that during the first $12 \mathrm{hr}$ following antigenic stimulation the immune response proceeded undisturbed by the presence of cytosine arabinoside, an inhibitor of DNA synthesis. If the inhibitor was allowed to act for more than $18 \mathrm{hr}$ after antigenic stimulation, the number of PFC was reduced significantly. Their observation showed that the induction of immune response occurred mostly during the first day and cell proliferation occurred later than the 2nd day. Thus, it is likely that beta-adrenergic stimulation with epinephrine exerts its immunosuppressive effect mainly inhibiting induction of antibody formation. In lymphocyte blastformation stimulated with phytohemagglutinin, Hadden et al. (1970) reported that isoproterenol given during the first $2 \mathrm{hr}$ of phytohemagglutinin stimulation suppressed the blastformation, and propranolol blocked the suppression of isoproterenol.

Exogenous cyclic AMP derivative showed inhibition or enhancement on antibody formation and its administration was effective mostly in the early phase of the immune response (Watson et al. 1973; Teh and Pactkau 1974; Kishimoto et al. 1977).

Our observation agreed to the view that the increase of intracellular cyclic AMP leads to precursor cell inactivation (Watson et al. 1973, 1975).

Exogenous cyclic AMP derivative and agents which increase intracellular cyclic AMP inhibit production of immunoglobulin from human peripheral lymphocytes (Patterson et al. 1976) and PFC from spleen cells of immunized mice (Melmon et al. 1974). In our experiment, however, epinephrine given $24 \mathrm{hr}$ before cell harvest for the PFC assay did not decrease the PFC number as compared with the control (Fig. 2), indicating that epinephrine does not suppress 19-S antibody formation in the experimental plan used in this study.

We found that beta-adrenergic stimulation suppressed 19-S antibody formation mainly in its inductive phase. Since the concentration of catecholamine used in this study was much higher than physiologic level, it is not known whether endo- 
genous catecholamines modulate antibody formation in vivo. But, our observations might justify further study on catecholamine effects on antibody formation in normal subjects and patients with atopic diseases.

\section{Acknowledgments}

We are gratefull to Dr. Robert Auerbach, Department of Zoology, University of Wisconsin, for allowing us to do this study in his laboratory.

\section{References}

1) Braun, W. \& Ishizuka, M. (1971) Cyclic AMP and immune responses II. Phosphodiesterase inhibitors as potentiators of polynucleotide, effects on antibody formation, J. Immunol, 107, 1036-1042.

2) Cunningham, A.J. \& Szenberg, A. (1968) Further improvements in the plaque technique for detecting single antibody-forming cells. Immunology, 14, 599-600.

3) Globerson, A. \& Auerbach, R. (1966) Primary antibody response in organ cultures. $J$. exp. Med., 124, 1001-1016.

4) Hadden, J.W., Hadden, E.M. \& Middletone, E., Jr. (1970) Lymphocyte blast transformation, 1. Demonstration of adrenergic receptors in human peripheral lymphocytes. Cellular Immunol., 1, 583-595.

5) Holtermann, O.A. \& Nordin, A.A. (1969) The effect of cytosine arabinoside upon the primary immune response in vitro. Proc. Soc. exp. Biol. Med., 132, 1003-1005.

6) Ishizuka, M., Gafni, M. \& Braun, W. (1970) Cyclic AMP effects on antibody formation and their similarities to hormone-mediated events. Proc. Soc. exp. Biol. Med., 134, 963-967.

7) Johnson, H.M., Blalock, J.E. \& Baron, S. (1977) Separation of mitogen-induced suppressor and helper cell activities during inhibition of interferon production by cyclic AMP. Cellular Immunol., 33, 170-179.

8) Kishimoto, T., Nishizawa, Y. Kikutani, H. \& Yamamura, Y. (1977) Biphasic effect of cyclic AMP on IgG production and on the changes of non-histone nuclear proteins induced with anti-immunoglobulin and enhancing soluble factor. J. Immunol., 118, $2027-2033$.

9) Lee, T., Busse, W.W. \& Reed., C.E. (1977) Effect of beta adrenergic agonist, prostaglandins, and cortisol on lymphocyte levels of cyclic adenosine monophosphate and glycogen: Abnormal lymphocytic metabolism in asthma. J. Allergy clin. Immunol., 59, 408-413.

10) Makino, S., Ikemori, R., Kashima, T. \& Fukuda, T. (1977) Comparison of cyclic adenosine monophosphate response of lymphocytes in normal and asthmatic subjects to norepinephrine and salbutamol. J. Allergy clin. Immunol., 59, 348-352.

11) Melmon, K.L., Bourne, H.R., Weinstein, Y., Shearer, G.M., Kram, J. \& Bauminger, S. (1974) Hemolytic plaque formation by leukocytes in vitro: Control by vasoactive hormones. $J$. clin. Invest., 53, 13-21.

12) Nakazawa, H., Hodbay, J., Townley, R. \& Chaperon, E. (1977) Effect of $\beta$-adrenergic blockade, pertussis vaccine and Freund's adjuvant on reaginic antibody response in mice. Int. Arch. Allergy appl. Immun., 53, 197-205.

13) Patterson, R., Suszko, I.M., Metzger, W.J. \& Roberts, M. (1976) In vitro production of IgE by human peripheral blood lymphocytes: Effect of cholera toxin and $\beta$ adrenergic stimulation. J. Immunol., 117, 97-101.

14) Reed, C.E., Benner, M., Lockey, S.D., Enta, T., Makino, S. \& Carr, R.H. (1972) On the mechanism of the adjuvant effect of bordetella pertussis vaccine. J. Allergy clin. Immunol., 49, 174-182.

15) Teh, H. \& Paetkau, V. (1974) Biphasic effect of cyclic AMP on an immune response. Nature (Lond.), 250, 505-507.

16) Watson, J. (1975) The influence of intracellular levels of cyclic nucleotides on cell 
proliferation and the induction of antibody synthesis. J. exp. Med., 141, 97-111.

17) Watson, J., Epstein, R. \& Cohn, M. (1973) Cyclic nucleotides as intracellular mediators of the expression of antigen-sensitive cells. Nature (Lond.), 246, 405-409.

18) Webb., D.R., Nowowiejski, I., Dauphinee, M. \& Talal, N. (1977) Antigen induced alterations in splenic prostaglandin and cyclic nucleotide levels in NZB mice. $J$. Immunol., 118, 446-450. 